\title{
Response surface methodological approach for optimizing removal of ciprofloxacin from aqueous solution using thermally activated persulfate/aeration systems
}

\author{
Shokoohi R., Shabanloo A., Vanaei M. and Torkshavand Z.* \\ Department of Environmental Health Engineering, School of Public Health, Hamadan University of Medical Sciences, Hamadan, Iran \\ Received: 22/11/2016, Accepted: 21/03/2017, Available online: 10/10/2017 \\ *to whom all correspondence should be addressed: Zahra.torkshavand@yahoo.com
}

\begin{abstract}
Being used in large quantities for some decades, antibiotics have been of little notice since their existence in the environment. Present study aims at investigating the optimization of Ciprofloxacin removal (CIP) in Thermally Activated Persulfate (TAP)/Aeration systems by Central Composite Design (CCD). The effect of operating parameters including initial $\mathrm{pH}$, CIP concentration, Persulfate concentration and temperature on the removal process was investigated in order to find out the optimum conditions. Typically, high temperature, high Persulfate dose, and low initial CIP concentration increased the removal efficiency of CIP. At the tested $\mathrm{pH}$ range of 3-11, the highest removal occurred at $\mathrm{pH}$ 3.93. Finally, the effects of $\mathrm{Mn}_{3} \mathrm{O}_{4}$ Nanoparticles, $\mathrm{N}_{2}$ gas, and $\mathrm{COD}$ reduction in optimal condition were studied. $\mathrm{Mn}_{3} \mathrm{O}_{4}$ Nanoparticles and $\mathrm{N}_{2}$ gas in optimized conditions increased the removal efficiency from 93.41 to 90.1 , respectively. The results showed that Thermally Activated Persulfate oxidation was the efficient process for the treatment of aqueous solution containing Ciprofloxacin due to the production of Sulfate radicals.
\end{abstract}

Keywords: Ciprofloxacin Removal, Thermally Activated Persulfate, $\mathrm{Mn}_{3} \mathrm{O}_{4}$ Nanoparticles

\section{Introduction}

Recently, the concern about environmental and health impacts of pharmaceutical compounds (PhCs) increased due to the high frequency of their detection in the environment, particularly as no legal requirements have been set for disposal into aqueous solution (Girardi et al., 2011; Verlicchi et al., 2012; Li et al., 2011). Among antimicrobial agents, Ciprofloxacin (CIP) is the most frequently identified antibiotic for being active against a broad spectrum of Gram-negative and Gram-positive bacteria (Babić et al., 2013; Van Doorslaer et al., 2014). Ciprofloxacin carried into the environment via disposals of sewage treatment plants, leaching from landfills, pharmaceutical industries, livestock activities and application of sewage sludge (Topp et al., 2008; Bobu et al., 2008). A number of promising waste water treatment methods have been used to remove CIP from aqueous solution, such as membrane separation(Avella et al., 2010), Ozonation (De Witte et al., 2010), Naofiltration (Sun et al., 2011), Photocatalytic Degradation (Van Doorslaer et al., 2011), Adsorption (Carabineiro et al., 2012) and Advanced Oxidation Process(Ji et al., 2014). Among these, Advanced Oxidation Processes (AOPs) are considered as an effective method to remove non-biodegradable organic pollutants such as CIP from aqueous solution (Bobu et al., 2008). Recently, an innovative treatment technology based on sulfate radicals has gained great attention as an alternative to conventional AOTs for the oxidation of organic pollutants(Deng et al., 2013; Epold et al., 2015). Due to its relatively high stability, aqueous solubility and low cost, Persulfate is commonly used as a source of sulfate radicals in field application. The main methods used for activation of Persulfate are heat, UV light or ultrasound activation, transition metal activation, alkaline activation, and peroxide activation(Chen and Su, 2012; Tsitonaki et al., 2010). Among these methods, Thermally Activated Persulfate (TAP) has already been applied for the removal of numerous organic contaminants (Ghauch and Tuqan, 2012; Huang et al., 2002; Tan et al., 2012). Consequently, the objective of this study is to investigate the removal of Ciprofloxacin (CIP) feasibility using Thermally Activated Persulfate/Aeration systems from aqueous solution. The effects of operating parameters including initial $\mathrm{pH}, \mathrm{CIP}$ concentration, Persulfate concentration and temperature on the removal process were investigated. Finally, the effect of $\mathrm{Mn}_{3} \mathrm{O}_{4}$ Nanoparticles, $\mathrm{N}_{2}$ gas, and COD reduction in the optimal condition was studied. In addition, changes in the solution $\mathrm{pH}$ throughout the experiments, the synergistic effect of various parameters and UV-VIS Spectral changes with reaction time in optimum conditions were also investigated.

\section{Materials and methods}

\subsection{Chemicals}

Ciprofloxacin $\left(\mathrm{C}_{17} \mathrm{H}_{18} \mathrm{FN}_{3} \mathrm{O}_{3}\right.$, purity $98 \%$, Catalog number: 17850), potassium peroxidisulfate $\left(\mathrm{K}_{2} \mathrm{O}_{8} \mathrm{~S}_{2}, \mathrm{MW}=270.32\right.$ $\mathrm{g} / \mathrm{mol}$, purity $99 \%)$, Potassium permanganate $\left(\mathrm{KMnO}_{4}\right.$, 
$\mathrm{MW}=158.03 \mathrm{~g} / \mathrm{mol}$, purity 99\%) and hydrazine monohydrate $\left(\mathrm{N}_{2} \mathrm{H}_{4} . \mathrm{H}_{2} \mathrm{O}, \mathrm{MW}=50.06 \mathrm{~g} / \mathrm{mol}\right.$, purity98 \%) were provided from Sigma Aldrich. All other chemicals and solvents such as ethanol, sulfuric acid and sodium hydroxide were of the highest quality commercially available and provided from Merck Co.

\subsection{Synthesis of $\mathrm{Mn}_{3} \mathrm{O}_{4}$ Nanoparticles}

0.04 moles of $\mathrm{KMnO}_{4}$ were dissolved in $200 \mathrm{ml}$ of the distilled water on a magnetic mixer at ambient temperature $\left(22^{\circ} \mathrm{C}\right) .200 \mathrm{ml}$ of the $\mathrm{N}_{2} \mathrm{H}_{4} \cdot \mathrm{H}_{2} \mathrm{O}$ solution containing 0.04 moles of $\mathrm{N}_{2} \mathrm{H}_{4} \cdot \mathrm{H}_{2} \mathrm{O}$ was quickly added to the above solution at the high speed mode of mixer. Following such conditions, the colour of the solution alters from purple to dark brown. While mixing the resulting solution quickly, its $\mathrm{pH}$ was fixed at 9 . Then, we slowly mixed the solution at $70^{\circ} \mathrm{C}$ for 15 minutes by the mixer. Over time while forming the structure of the Nanoparticles, the color of the solution transformed from dark brown to brown-orange and, at the end of the 15 minutes, the formed particles appeared as colony-evident. At this point, the solution was cooled down to reach the room temperature and the settled particles separated through centrifugation. The resulting particles were then rinsed twice with the distilled water and once with the ethanol then they were kept, to get dried out, for 8 hours in an oven at $50^{\circ} \mathrm{C}$ (Gibot and Laffont, 2007; Cushing et al., 2004; Li et al., 2009). The FE-SEM (MIRA 3 TESCAN-XMU) and FTIR (TENSOR27, Germany) analysis have been used to determine the characteristics of the synthesized Nanoparticles.

\subsection{Experimental Procedure}

This experimental study was carried out in batch procedure and laboratory scale.

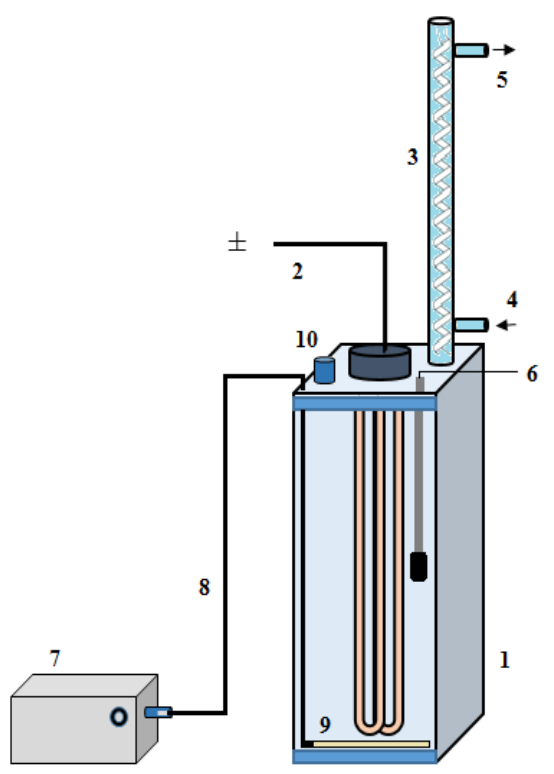

Figure 1. The schematic of the experimental setup (1-Rectangular Cube Glass Reactor, 2-Heater, 3Refrigerant Return, 4- Cold Water Inlet, 5-Cold Water Outlet, 6-pH meter, 7-Air Pump, 8-Air Hose, 9-Diffuser, 10Place Of Sampling)
Specific volumes of substrate stock solution were transferred into a rectangular cube glass reactor $(\mathrm{H}=35$ $\mathrm{cm}, \mathrm{V}=4.5 \mathrm{~L}$ ) and appropriate volumes of Persulfate were added. The reaction time of each degradation experiment was 30 minutes. Control experiments were carried out with substrate only, substrate-Persulfate (without thermal), and substrate-thermal (without Persulfate) under identical conditions. For all of the control experiments, the removal of the substrate was found to be negligible.

The oxidation was initiated once appropriate volumes of the $\mathrm{K}_{2} \mathrm{~S}_{2} \mathrm{O}_{8}$ stock solution were added. Synthetic solution for CIP was prepared by dissolving accurately weighed amounts of powdered compound in the ultra-pure water. The quantitative determination of CIP in the supernatant was analysed by measuring optical density at $271 \mathrm{~nm}$ on a UV-Visible spectrophotometer (Hach-Lange DR 5000). The initial solution $\mathrm{pH}$ was adjusted to the desirable level by $1 \mathrm{M}$ $\mathrm{H}_{2} \mathrm{SO}_{4}$ or $1 \mathrm{M} \mathrm{NaOH}$ for all of the experiments. The solution $\mathrm{pH}$ was adjusted by adding $1 \mathrm{~mol} / \mathrm{L} \mathrm{NaOH}$ or $1 \mathrm{~mol} / \mathrm{L} \mathrm{H}_{2} \mathrm{SO}_{4}$. These studies were performed in the water and the waste water laboratory of Hamadan University of Medical Sciences in the summer of 2016. The schematic of the experimental setup employed in the present study is shown in Fig. 1. The UV-Visible Spectra of the CIP aqueous solutions $(15 \mathrm{mg} / \mathrm{L})$ with different $\mathrm{pH}$ value are shown in Fig. 2. It is evident from Fig. 2 that the removal of CIP at 271 $\mathrm{nm}$ increased and shifted to a shorter wavelength when the $\mathrm{pH}$ values decreased below the natural $\mathrm{pH}$ value of the CIP aqueous solution ( $\mathrm{pH} 7.0)$.

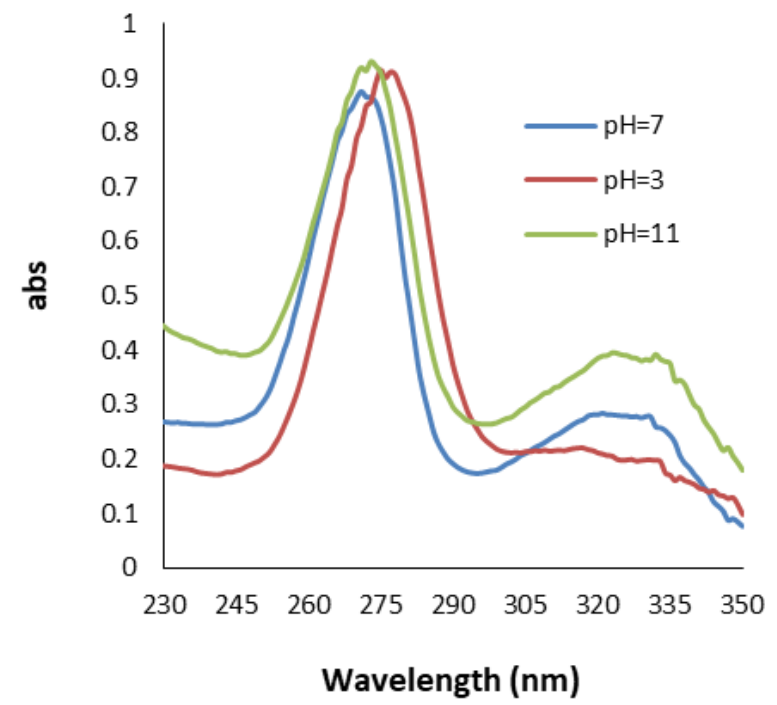

Figure 2. The UV-Visible Spectral changes of CIP aqueous solution $(15 \mathrm{mg} / \mathrm{L})$ with different $\mathrm{pH}$ values

\subsection{Designing of the Experiment}

Response Surface Methodology (RSM) is a combination of the statistical and the mathematical methods used in order to identify the best conditions for the experiments with the least experiments performed. 
Table 1. Independent variables and their levels used in the response surface design

\begin{tabular}{cccccccc}
\hline \multirow{2}{*}{ Factors } & \multirow{2}{*}{ Symbol } & \multicolumn{6}{c}{ Coded level } \\
\cline { 2 - 7 } & & $\mathbf{- 2}$ & $\mathbf{- 1}$ & $\mathbf{0}$ & $\mathbf{1}$ & $\mathbf{2}$ \\
\hline $\mathrm{pH}$ & $\mathrm{X}_{1}$ & 3 & 5 & 7 & 9 & 11 \\
\hline $\begin{array}{c}\mathrm{CIP} \\
\text { concentration }\end{array}$ & $\mathrm{X}_{2}$ & 5 & 10 & 15 & 20 & 25 \\
\hline Persulfate dose & $\mathrm{X}_{3}$ & 2 & 4 & 6 & 8 & 10 \\
\hline Temperature & $\mathrm{X}_{4}$ & 50 & 55 & 60 & 65 & 70 \\
\hline
\end{tabular}

The experiments were designed by Design-Expert software version 7.0. In the present study, to collect the maximum information using the fewer number of experiments, a CCD design combining with RSM for four major variables $(\mathrm{pH}$ $\left(X_{1}\right)$, Ciprofloxacin concentration $\left(X_{2}\right)$, Persulfate dose $\left(X_{3}\right)$ and temperature $\left(X_{4}\right)$ ), each with five separate levels, was applied as an experimental design model. The range of the independent variables and their levels investigated in the work are given in Table 1. Table 2 shows the experimental conditions according to the factorial design.

Table 2. Response Surface CCD design and results

\begin{tabular}{|c|c|c|c|c|c|}
\hline Run & $\mathrm{pH}$ & Ciprofloxacin (mg/l) & Persulfate $(\mathrm{mmol} / \mathrm{l})$ & Temperature & Removal efficiency \\
\hline 1 & 5 & 10 & 8 & 55 & 63 \\
\hline 2 & 7 & 15 & 10 & 60 & 74 \\
\hline 3 & 11 & 15 & 6 & 60 & 16 \\
\hline 4 & 7 & 15 & 6 & 60 & 67 \\
\hline 5 & 7 & 25 & 6 & 60 & 63 \\
\hline 6 & 9 & 10 & 4 & 65 & 38 \\
\hline 7 & 5 & 10 & 8 & 65 & 73 \\
\hline 8 & 5 & 20 & 8 & 55 & 56 \\
\hline 9 & 7 & 15 & 2 & 60 & 37 \\
\hline 10 & 9 & 20 & 4 & 65 & 35 \\
\hline 11 & 7 & 15 & 6 & 60 & 67 \\
\hline 12 & 7 & 15 & 6 & 60 & 67 \\
\hline 13 & 5 & 10 & 4 & 55 & 54 \\
\hline 14 & 9 & 10 & 8 & 55 & 37 \\
\hline 15 & 7 & 5 & 6 & 60 & 68 \\
\hline 16 & 7 & 15 & 6 & 60 & 67 \\
\hline 17 & 9 & 20 & 8 & 65 & 47 \\
\hline 18 & 7 & 15 & 6 & 70 & 79 \\
\hline 19 & 9 & 10 & 8 & 65 & 45 \\
\hline 20 & 9 & 10 & 4 & 55 & 33 \\
\hline 21 & 9 & 20 & 4 & 55 & 30 \\
\hline 22 & 7 & 15 & 6 & 60 & 67 \\
\hline 23 & 7 & 15 & 6 & 60 & 67 \\
\hline 24 & 3 & 15 & 6 & 60 & 81 \\
\hline 25 & 5 & 20 & 4 & 55 & 40 \\
\hline 26 & 5 & 20 & 8 & 65 & 70 \\
\hline 27 & 5 & 20 & 4 & 65 & 59 \\
\hline 28 & 7 & 15 & 6 & 50 & 41 \\
\hline 29 & 5 & 10 & 4 & 65 & 63 \\
\hline 30 & 9 & 20 & 8 & 55 & 33 \\
\hline
\end{tabular}

\section{Results and discussion}

\subsection{Analysis FE-SEM and FTIR of $\mathrm{Mn}_{3} \mathrm{O}_{4}$ Nanoparticles}

The morphology of the nanoparticles characterized by FESEM is shown in Fig. 3a. From the micrograph, it is observed that the Nanoparticles were agglomerated but were almost uniform in the size. The particle morphology is either spherical or cubic like, having a diameter of between 8 and $23 \mathrm{~nm}$. Figure 3b shows the FT-IR spectra of the obtained $\mathrm{Mn}_{3} \mathrm{O}_{4}$ powders by the thermal decomposition. It can be achieved that this sample shows several peaks in the range of 1000-1637, also in the range of 400-1000, and also two peaks in the range of 3324- 3436. Absorption peaks in the range of $400-1000$ indicates the presence of Octahydrals of $\mathrm{MnO}_{x}$ in the sample. Also, the presence of peaks in the range: $1637-1000$ defines the vibrational bands of $\mathrm{O}-\mathrm{H}$ attached to the manganese atoms. The peaks in the area of 3324 and 3436 also introduce the $\mathrm{NH}$ band on hydrazine monohydrate with the molecular formula of $\mathrm{N}_{2} \mathrm{H}_{4}$. The results of this analysis stay constant with the results obtained from the previous studies to evaluate the functional groups in the production of nanoparticles of $\mathrm{Mn}_{3} \mathrm{O}_{4}$ (Gibot and Laffont, 2007).

\subsection{Effect of Temperature and Initial CIP Concentration}

The effect of temperature $\left(50-70^{\circ} \mathrm{C}\right)$ and initial CIP concentration $(5-25 \mathrm{mg} / \mathrm{L}$ ) on the CIP degradation rate is depicted in Fig. 4. The results obtained show that the CIP 
degradation in the heat-activated Persulfate system is temperature dependent. In general, higher temperatures provide more energy to rupture $\mathrm{O}-\mathrm{O}$ bonds of Persulfate, and more readily produce reactive species such as sulfate radicals $\mathrm{SO}_{4}^{-}$and indirectly hydroxyl radicals $\mathrm{OH}^{*}$, therefore leading to faster CIP degradation in aqueous solution(Huang et al., 2002). Complete removal is observed for reactions carried out at $70{ }^{\circ} \mathrm{C}$ over 30 minutes. The

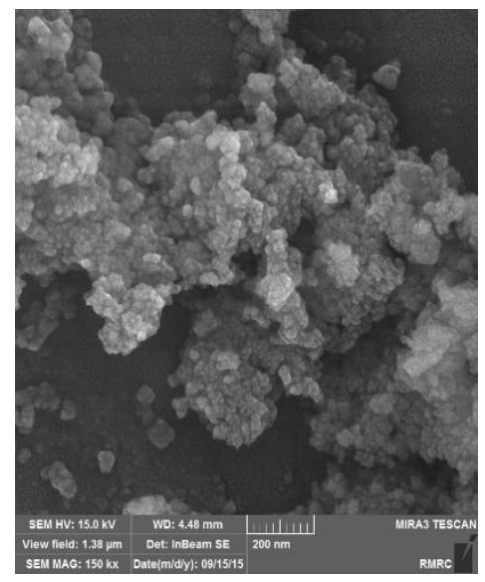

(a) results of this analysis consistently match with the results obtained from the previous studies(Ghauch et al., 2012). It is obvious that as the initial CIP concentration increases, the degradation rate of CIP decreases. Theoretically, at a high CIP concentration, the amount of CIP to be degraded by sulfate radicals is small compared with the total CIP. Similar results indicating an increase in removal rate following a decrease in initial CIP concentration were also reported by Deng et al (Deng et al., 2013).

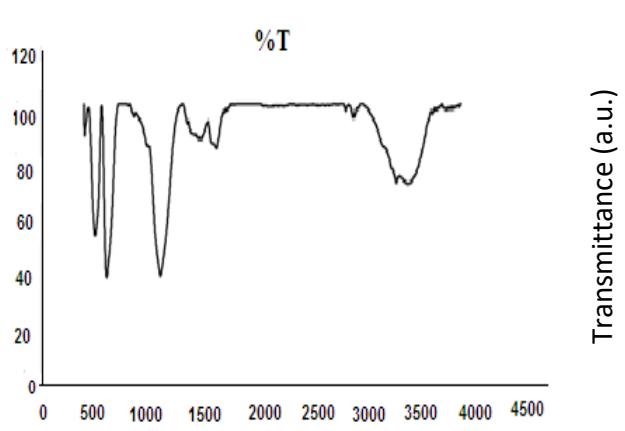

Wave number $\left(\mathrm{cm}^{-1}\right)$

(b)

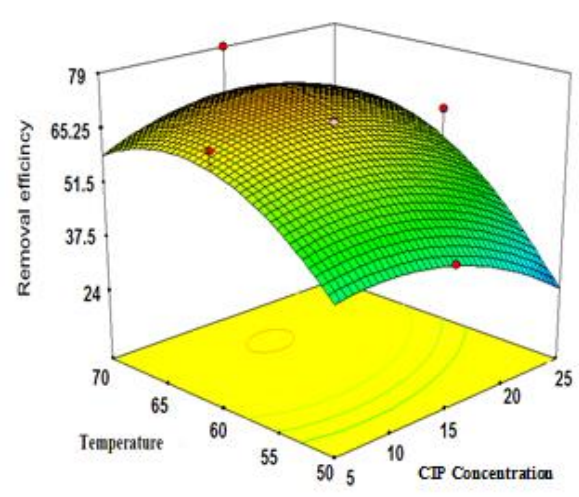

Figure 4. The effect of temperature and Initial CIP concentration on the CIP degradation rate

\subsection{Influence of Solution $\mathrm{pH}$ On CIP Degradation}

The influence of $\mathrm{pH}$ on the CIP degradation rate was explored by adjusting the solution $\mathrm{pH}$ to 3-11 (Figure 5). The results showed that the optimum $\mathrm{pH}$ value was 3.93, leading to a faster CIP degradation in aqueous solution. Then, the removal dropped significantly at $\mathrm{pH} 11$. The $\mathrm{pH}$ of the activated Persulfate reaction has a significant effect on the efficiency of CIP removal, although degradation reactions at acidic $\mathrm{pH}$ most of the time improve the degradation of the contaminants by forming hydroxyl radicals (Matzek and Carter, 2016). In acidic conditions, auto-catalysis is more likely to happen along with the production of sulfate radicals resulting in higher CIP degradation(Johnson et al., 2008; Ghauch et al., 2012). A similar finding was also reported by Liang et al. (2007), who found out that phosphate and sulfate ions did not inhibit the degradation of aromatic compounds at acidic $\mathrm{pH}$ values(Liang et al., 2007).

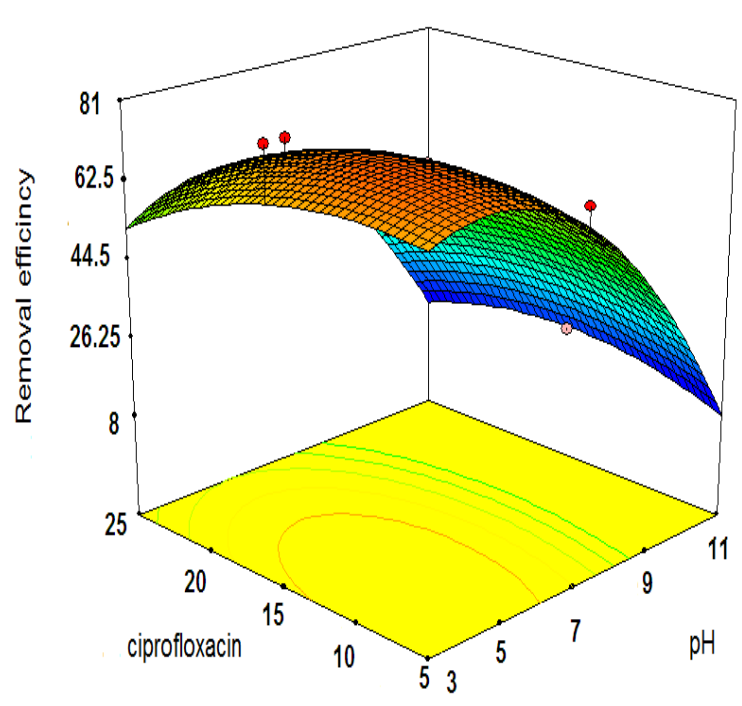

Figure 5. The effect of solution $\mathrm{pH}$ on CIP degradation

\subsection{Effect of Persulfate Dosage}

The effect of initial Persulfate concentration on the CIP degradation was investigated within the Persulfate concentration ranges of 2-10 $\mathrm{mM}$. 


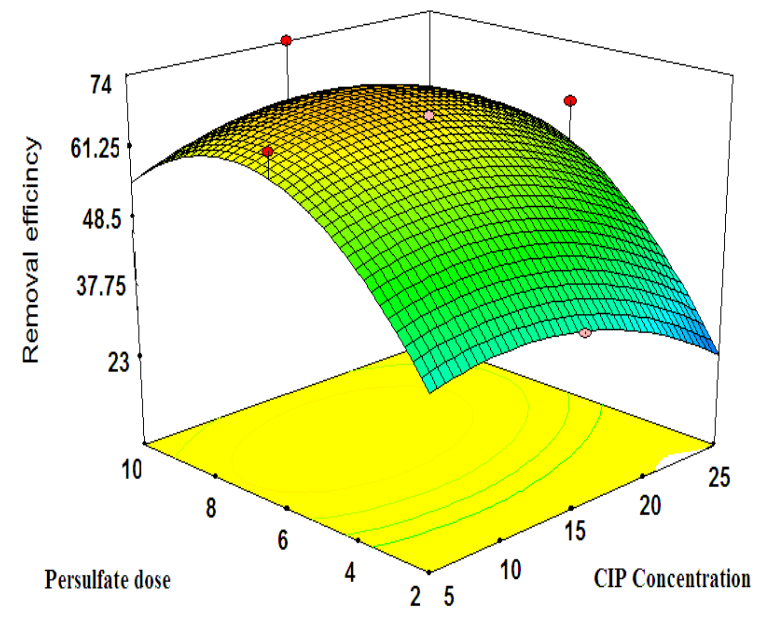

Figure 6. The Effect of initial Persulfate concentration on CIP degradation

It is observed that CIP decomposition was appreciably enhanced with increasing the concentration of Persulfate. This observation can be attributed to a higher amount of reactive radicals (e.g., $\mathrm{SO}^{\circ-}$ and $\mathrm{HO}^{\circ}$ ) at higher levels of Persulfate. It is interesting to mention that the concentration of CIP was firstly decreased, and then recovered back to the initial level when the Persulfate was not activated by heat(Ji et al., 2014). This finding is consistent with the results of Chaoqun Tan et al., who reported that the higher Persulfate dose would lead to a higher diuron degradation rate(Tan et al., 2012).

\subsection{Statistical Analysis and the Model Fitting}

The CCD model was used to evaluate the interactive effects of parameters for optimizing the removal of Ciprofloxacin using the Thermal Activated Persulfate. There were a total of 30 runs for optimizing the variables in the CCD statistical design. Design expert was used for ANOVA software analysis of the experimental data obtained earlier. The model was found to be adequate for predictions made within the range of experimental variables. The model expressed by Eq. (1), where the variables take their coded values, represents the efficiency of Ciprofloxacin removal $(\mathrm{Y})$ as a function of $\mathrm{pH}(\mathrm{A})$, Ciprofloxacin concentration (B), Persulfate dose (C) and temperature (D).

$\mathrm{R} 1=+67.00-12.75 * \mathrm{X}_{1}-1.92 * \mathrm{X}_{2}+6.08 * \mathrm{X}_{3}+6.67 * \mathrm{X}_{4}+1.25 * \mathrm{X}_{1} * \mathrm{X}_{2}-1.25 * \mathrm{X}_{1} * \mathrm{X}_{3}-1.25 * \mathrm{X}_{1} * \mathrm{X}_{4}+0.75 * \mathrm{X}_{2} * \mathrm{X}_{3}+1.25 * \mathrm{X}_{2} * \mathrm{X}_{4}$ $+0.50 * X_{3} * X_{4}-5.90 * X_{1}{ }^{2}-1.90 * X_{2}^{2}-4.40 * X_{3}^{2}-3.27 * X 42(1)$

The statistical significance of the factors and their interactions at various levels of probability are Shown in Table 3.

Table 3. ANOVA for Response Surface Quadratic Model Analysis of Variance Table

\begin{tabular}{|c|c|c|c|c|c|c|}
\hline Source & Sum of Squares & df & Mean Square & F Value & p-value Prob > F & \\
\hline Model & 7480.88 & 14 & 534.35 & 9.97 & $<0.0001$ & significant \\
\hline $\mathrm{X}_{1-\mathrm{pH}}$ & 3901.50 & 1 & 3901.50 & 72.78 & $<0.0001$ & \\
\hline $\mathrm{X}_{2}$-Ciprofloxacin & 88.17 & 1 & 88.17 & 1.64 & 0.2191 & \\
\hline $\mathrm{X}_{3}$-Persulfate & 888.17 & 1 & 888.17 & 16.57 & 0.0010 & \\
\hline $\mathrm{X}_{4}$-temperature & 1066.67 & 1 & 1066.67 & 19.90 & 0.0005 & \\
\hline $\mathrm{X}_{1} \mathrm{X}_{2}$ & 25.00 & 1 & 25.00 & 0.47 & 0.5051 & \\
\hline $\mathrm{X}_{1} \mathrm{X}_{3}$ & 25.00 & 1 & 25.00 & 0.47 & 0.5051 & \\
\hline $\mathrm{X}_{1} \mathrm{X}_{4}$ & 25.00 & 1 & 25.00 & 0.47 & 0.5051 & \\
\hline $\mathrm{X}_{2} \mathrm{X}_{3}$ & 9.00 & 1 & 9.00 & 0.17 & 0.6878 & \\
\hline $\mathrm{X}_{2} \mathrm{X}_{4}$ & 25.00 & 1 & 25.00 & 0.47 & 0.5051 & \\
\hline $\mathrm{X}_{3} \mathrm{X}_{4}$ & 4.00 & 1 & 4.00 & 0.075 & 0.7885 & \\
\hline $\mathrm{X}_{1}{ }^{2}$ & 953.44 & 1 & 953.44 & 17.79 & 0.0007 & \\
\hline $\mathrm{X}_{2}{ }^{2}$ & 98.58 & 1 & 98.58 & 1.84 & 0.1951 & \\
\hline$X_{3}{ }^{2}$ & 530.01 & 1 & 530.01 & 9.89 & 0.0067 & \\
\hline$X_{4}^{2}$ & 293.44 & 1 & 293.44 & 5.47 & 0.0335 & \\
\hline Residual & 804.08 & 15 & 53.61 & & & \\
\hline Lack of Fit & 804.08 & 10 & 80.41 & & & \\
\hline Pure Error & 0.000 & 5 & 0.000 & & & \\
\hline Cor Total & 8284.97 & 29 & & & & \\
\hline
\end{tabular}

R-Squared: 0.9029, Adj R-Squared: 0.8124, Pred R-Squared: 0.4410

\subsection{Combined $\mathrm{Mn}_{3} \mathrm{O}_{4}$ Nanoparticles/Thermal Activated Persulfate}

The Combined $\mathrm{Mn}_{3} \mathrm{O}_{4}$ Nanoparticles/Thermal Activation Persulfate system was studied in order to facilitate the activator regeneration in Persulfate systems, increase efficiency and reduce the time of retention. To evaluate the efficacy of CIP degradation by combined Thermal Activated Persulfate and $\mathrm{Mn}_{3} \mathrm{O}_{4}$ Nanoparticles, the experiment were performed in optimum conditions and $\mathrm{Mn}_{3} \mathrm{O}_{4}=0.5 \mathrm{~g} / 4.5 \mathrm{~L}$
(Persulate dose=7.1mM, pH=3.93, CIP= $15.2 \mathrm{mg} / \mathrm{l}$, Time= $30 \mathrm{~min})$. The removal efficiency results and the synergistic effect of different conditions are shown in Fig. 7. The results showed that the removal efficiency of optimal condition/ $\mathrm{Mn}_{3} \mathrm{O}_{4}$ (93.41\%) is higher than the other conditions. Thus, the optimal condition/ $\mathrm{Mn}_{3} \mathrm{O}_{4}$ ((Persulate dose=7.1mM, pH=3.93, $\mathrm{ClP}=15.2 \mathrm{mg} / \mathrm{l}, \mathrm{Mn}_{3} \mathrm{O}_{4}=0.5 \mathrm{~g} / 4.5 \mathrm{~L}$, Time $=30 \mathrm{~min}, \mathrm{~N}_{2}$ flow $=250 \mathrm{ml} / \mathrm{min}$ ) was recognized to be the best condition for the removal of Ciprofloxacin antibiotic. 

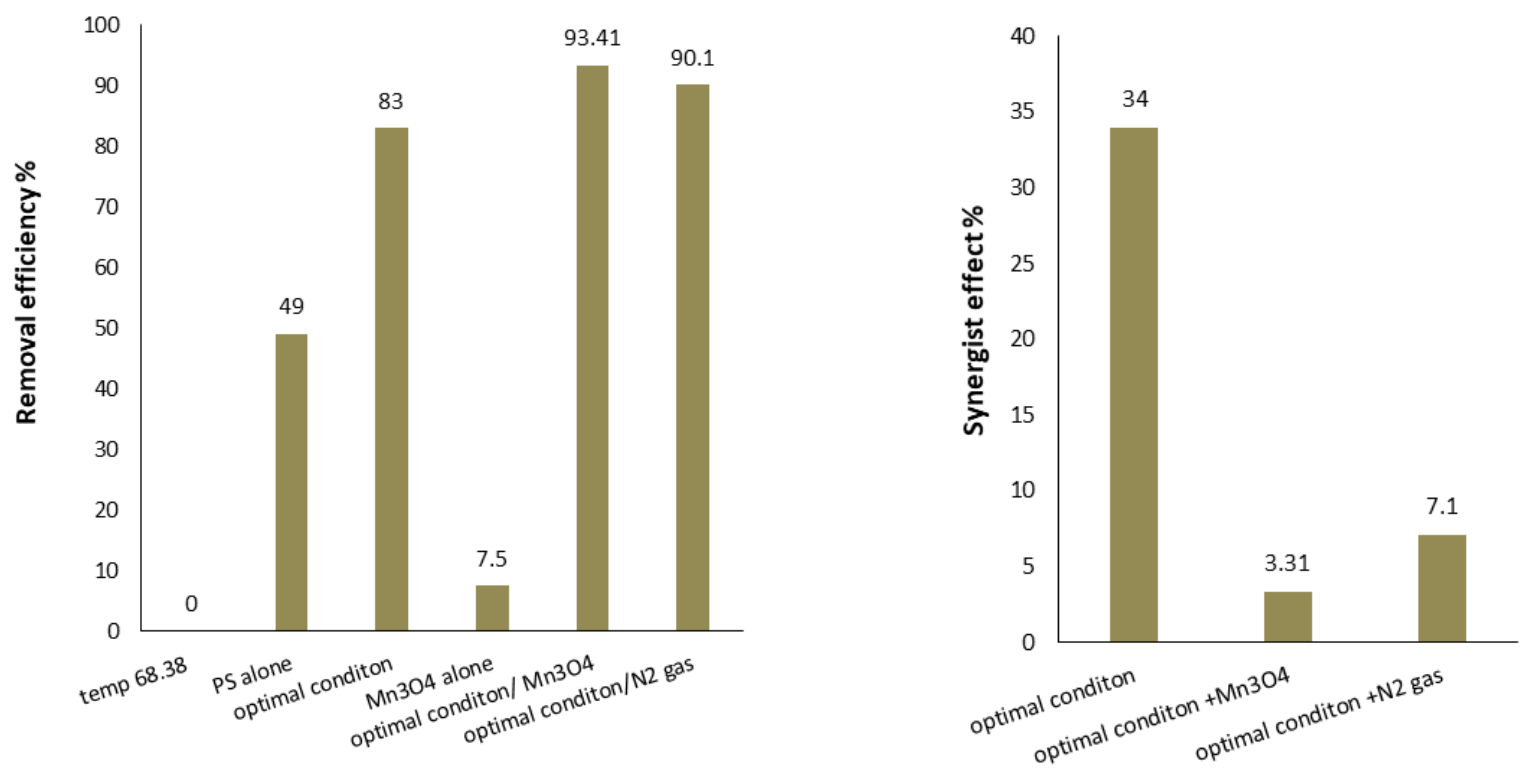

Figure 7. Removal Efficiency and Synergistic Effect of the CIP in the aqueous solutions in various conditions (Persulate dose=7.1mM, pH=3.93, $\mathrm{ClP}=15.2 \mathrm{mg} / \mathrm{l}, \mathrm{Mn}_{3} \mathrm{O}_{4}=0.5 \mathrm{~g} / 4.5 \mathrm{~L}$, Time $=30 \mathrm{~min}, \mathrm{~N}_{2}$ flow $=250 \mathrm{ml} / \mathrm{min}$ )

\section{Conclusions}

This study was aimed at investigating the efficiency of thermal activated Persulfate in the removal of Ciprofloxacin from aqueous solution. The experimental data demonstrated that the thermal activated Persulfate is much able to efficiently remove the Ciprofloxacin from aqueous solution. The Central Composite Design CCD was found out to be a valuable tool in establishing optimal conditions throughout a Response Surface Study. Four variables, including $\mathrm{pH}$, Ciprofloxacin concentration, Persulfate dose and temperature were regarded as factors in the optimization study. The maximum removal efficiency of the Ciprofloxacin was determined at the following conditions: $\mathrm{pH}=3.93,15.2 \mathrm{mg} / \mathrm{l}$ Ciprofloxacin, Persulfate concentration $=7.10 \mathrm{mM}$ and temperature $=68.38{ }^{\circ} \mathrm{C}$. The findings in this study strongly suggest that the advanced oxidation technologies prove to be promising techniques for the treatment of the waste water and the aqueous solution containing Ciprofloxacin (CIP).

Acknowledgements: The research was supported by Hamadan University of Medical Sciences, Hamadan, Iran (Grant No. 960115368).

\section{References}

Avella A., Delgado L.F., Görner T., Albasi C., Galmiche M. and De Donato P. (2010), Effect of cytostatic drug presence on extracellular polymeric substances formation in municipal wastewater treated by membrane bioreactor, Bioresource Technology, 101, 518-526.

Babić S., Periša M. and Škorić I. (2013), Photolytic degradation of norfloxacin, enrofloxacin and ciprofloxacin in various aqueous media. Chemosphere, 91, 1635-1642.

Bobu M., Yediler A., Siminiceanu I. and Schulte-Hostede S. (2008), Degradation studies of ciprofloxacin on a pillared iron catalyst, Applied Catalysis B: Environmental, 83, 15-23.
Carabineiro S., Thavorn-Amornsri T., Pereira M., Serp P. and Figueiredo J. (2012), Comparison between activated carbon, carbon xerogel and carbon nanotubes for the adsorption of the antibiotic ciprofloxacin, Catalysis Today, 186, 29-34.

Chen W.-S. and Su Y.-C. (2012), Removal of dinitrotoluenes in wastewater by sono-activated persulfate, Ultrasonics sonochemistry, 19, 921-927.

Cushing B.L., Kolesnichenko V.L. and O'Connor C.J. (2004), Recent advances in the liquid-phase syntheses of inorganic nanoparticles, Chemical Reviews, 104, 3893-3946.

De Witte B., Van Langenhove, H., Demeestere, K., Saerens, K., De Wispelaere, P. \& Dewulf, J. 2010. Ciprofloxacin ozonation in hospital wastewater treatment plant effluent: effect of $\mathrm{pH}$ and $\mathrm{H} 2 \mathrm{O}$ 2. Chemosphere, 78, 1142-1147.

Deng J., Shao Y., Gao N., Deng Y., Zhou S. and Hu X. (2013), Thermally activated persulfate (TAP) oxidation of antiepileptic drug carbamazepine in water, Chemical Engineering Journal, 228, 765-771.

Epold I., Trapido M. and Dulova N. (2015), Degradation of levofloxacin in aqueous solutions by Fenton, ferrous ionactivated persulfate and combined Fenton/persulfate systems, Chemical Engineering Journal, 279, 452-462.

Ghauch A. and Tuqan A.M. (2012), Oxidation of bisoprolol in heated persulfate/H 2 O systems: kinetics and products, Chemical Engineering Journal, 183, 162-171.

Ghauch A., Tuqan A.M. and Kibbi N. (2012), Ibuprofen removal by heated persulfate in aqueous solution: a kinetics study, Chemical Engineering Journal, 197, 483-492.

Gibot P. and Laffont L. (2007), Hydrophilic and hydrophobic nanosized $\mathrm{Mn}_{3} \mathrm{O}_{4}$ particles, Journal of Solid State Chemistry, 180, 695-701.

Girardi C., Greve J., Lamshöft M., Fetzer I., Miltner A., Schäffer A. and Kästner M. (2011), Biodegradation of ciprofloxacin in water and soil and its effects on the microbial communities, Journal of Hazardous Materials, 198, 22-30. 
Huang K.-C., Couttenye R.A. and Hoag G.E. (2002), Kinetics of heat-assisted persulfate oxidation of methyl tert-butyl ether (MTBE), Chemosphere, 49, 413-420.

Ji Y., Ferronato C., Salvador A., Yang X. and Chovelon J.-M. (2014), Degradation of ciprofloxacin and sulfamethoxazole by ferrous-activated persulfate: implications for remediation of groundwater contaminated by antibiotics, Science of the Total Environment, 472, 800-808.

Johnson R.L., Tratnyek P.G. and Johnson R.O.B. (2008), Persulfate persistence under thermal activation conditions. Environmental Science and Technology, 42, 9350-9356.

Li X., Zhou L., Gao J., Miao H., Zhang H. and Xu J. (2009), Synthesis of $\mathrm{Mn}_{3} \mathrm{O}_{4}$ nanoparticles and their catalytic applications in hydrocarbon oxidation, Powder Technology, 190, 324-326.

Li Z., Hong H., Liao L., Ackley C.J., Schulz L.A., Macdonald R.A., Mihelich A.L. and Emard S.M. (2011), A mechanistic study of ciprofloxacin removal by kaolinite, Colloids and Surfaces $B$ : Biointerfaces, 88, 339-344.

Liang C., Wang Z.-S. and Bruell C.J. (2007), Influence of pH on persulfate oxidation of TCE at ambient temperatures, Chemosphere, 66, 106-113.

Matzek L.W. and Carter K.E. (2016), Activated persulfate for organic chemical degradation: a review, Chemosphere, 151, 178-188.

Sun S.P., Hatton T.A. \& Chung, T.-S. (2011), Hyperbranched polyethyleneimine induced cross-linking of polyamide-imide nanofiltration hollow fiber membranes for effective removal of ciprofloxacin, Environmental Science \& technology, 45, 4003-4009.

Tan C., Gao N., Deng Y., An N. and Deng J. (2012), Heat-activated persulfate oxidation of diuron in water, Chemical Engineering Journal, 203, 294-300.

Topp E., Monteiro S.C., Beck A., Coelho B.B., Boxall A.B., Duenk P.W., Kleywegt S., Lapen D.R., Payne M. and Sabourin L. (2008), Runoff of pharmaceuticals and personal care products following application of biosolids to an agricultural field, Science of the Total Environment, 396, 52-59.

Tsitonaki A., Petri B., Crimi M., Mosbæk H., Siegrist R.L. and Bjerg P.L. (2010), In situ chemical oxidation of contaminated soil and groundwater using persulfate: a review, Critical Reviews in Environmental Science and Technology, 40, 55-91.

Van Doorslaer, X., Demeestere, K., Heynderickx, P. M., Van Langenhove, H. \& Dewulf, J. 2011. UV-A and UV-C induced photolytic and photocatalytic degradation of aqueous ciprofloxacin and moxifloxacin: reaction kinetics and role of adsorption. Applied Catalysis B: Environmental, 101, 540-547.

Van Doorslaer X., Dewulf J., Van Langenhove H. and Demeestere K. (2014), Fluoroquinolone antibiotics: an emerging class of environmental micropollutants, Science of the Total Environment, 500, 250-269.

Verlicchi P., Al Aukidy M. and Zambello E. (2012), Occurrence of pharmaceutical compounds in urban wastewater: removal, mass load and environmental risk after a secondary treatment-a review, Science of the total environment, 429, 123-155. 